\section{Feasibility analysis of the development of an oil field: a real options approach in a production sharing agreement}

\author{
Marcelo Nunes Fonseca \\ Universidade Federal de Itajubá, IEPG, Itajubá, Brazil \\ Edson Oliveira Pamplona \\ Universidade Federal de Itajubá, IEPG, Itajubá, Brazil \\ Paulo Rotela Junior \\ Universidade Federal da Paraíba, DEP, João Pessoa, Brazil \\ Victor Eduardo de Mello Valério \\ Universidade Federal de Itajubá, IEPG, Itajubá, Brazil
}

\begin{abstract}
Purpose - The aim of this research is to analyze the feasibility of developing a real oil field in Africa under a production sharing agreement, through the application of the real options theory.
\end{abstract}

Design/methodology/approach - The research was conducted according to the principles of modeling and simulation, based on a structure that consists of three phases, in order to facilitate project feasibility analysis.

Findings - Initially, according to the traditional method, we suggest that the decision-maker does not invest in the development of the field. However, by incorporating uncertainty into the decision-making process, other results were obtained. Although reduced, we attested that there is a likelihood of feasibility. Next, by using the binomial model to represent the process of oil barrel price diffusion, the asset value is calculated considering the flexibility of delaying the development of the field.

Originality/value - The results show that, if a manager has the right to invest in the future and wait for better oil prices, postponing the development of an oil field adds value to his assets. The proposed method is a contribution that offers subsidies to improve decisionmaking processes to evaluate investments.

Keywords - Feasibility analysis; real options; production sharing agreement; oil exploration and production.
574

Received on

01/28/2016

Approved on

07/24/2017

\section{Responsible editor:}

Prof. Dr. Eduardo Contani

Evaluation process:

Double Blind Review

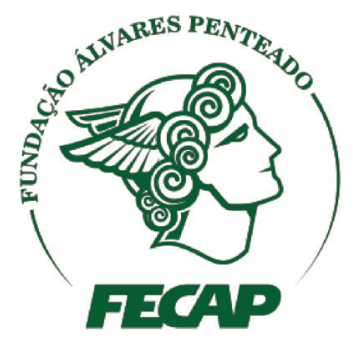

Review of Business Management 


\section{Introduction}

Evaluating an oil exploration project is a complex and challenging operation. Increasing attention is being given to planning the development of oil and gas fields, considering the discovery of large reserves of these resources over the last decade (Gupta \& Grossmann, 2011).

Thus, Helland and Torgersen (2014) warn that assessing investments in oil projects must be done with great care, mainly due to uncertainties in several variables referring to valuation. Uncertainties are defined as deviations from the expected result.

The main sources of uncertainty in decision-making concerning the value of a project are the quantity and quality of a field's reserves an internal variable defined by geological factors - and oil prices - an external variable defined by market factors (Gupta \& Grossman, 2014; Helland \& Torgersen, 2014; Salomão \& Grell, 2001).

According to Schiozer, Ligero and Santos (2004), these uncertainties can influence the success of oil exploration and production, and, as investments and oil exploration costs have increased rapidly over the past decade, a consistent analytical process that provides an optimal decision is crucial while analyzing investment projects within the oil industry (Helland \& Torgersen, 2014).

There are a number of analytical tools that can be used, particularly to evaluate projects involving investments in oil exploration, among which the Discounted Cash Flow (DCF) is a highlight. However, this technique does not take into account the value of managerial flexibility in these types of projects (Helland \& Torgersen, 2014).

In this context, the Real Options Theory (ROT) is a method capable of incorporating the managerial flexibilities that traditional methods fail to incorporate. According to Fleten, Gunnerud, Hem and Svendsen (2011), valuation through real options has been applied to oil projects for a long time, since they offer several attributes that make them suitable for such an evaluation.

As to the methods used to calculate option values, the Black \& Scholes model and the binomial tree can be mentioned. In these models, definition requires six variables: the present value of future cash flows, the present value of investments, the risk-free interest rate, the option expiration period, the basic asset's dividend (or convenience) rate, and the volatility of the basic asset. Among these variables, volatility is highlighted, since, according to Costa Lima and Suslick (2006), this parameter is key and hard to estimate, because there is no historical series of project values.

This scenario of uncertainty has been affecting investments in oil exploration and production in Africa, in which the field of this study is located. For confidentiality's sake, only the continent is mentioned; the name of the field and its country of origin has been kept confidential. According to an Energy Information Administration (2015) publication, only one company was successful in pre-salt exploration in that country. To the aforementioned publication, a combination of disappointing results and geological complexity, aggravated by low oil prices, resulted in reduced investments in presalt areas.

Considering these premises, the main objective of this study is to analyze the feasibility of developing an oil field in Africa, in which a production sharing contract is adopted. In order to attain the objective of this study, a combination of techniques are applied in a real case with the following specific objectives: (i) to measure the production profile through a three-dimensional (3D) model using Eclipse and Petrel ${ }^{\circ}$ software; (ii) to estimate the behavior of oil prices through geometric Brownian motion (GBM); and (iii) to calculate asset value considering the flexibility to postpone the development of the field using the ROT. 


\section{Contractual arrangements}

As to the ownership of liquid and gaseous hydrocarbons found in that country, the state attributes exclusive rights over these resources to the national concessionaire. In this manner, any oil company (OC) that expects to explore oil in the country should associate with the concessionaire.

Concerning the forms of association, the most frequently used models in that country are:

(i) Production sharing agreement (PSA); and

(ii) Risk service contract (RSC).

\section{I Production sharing agreement (PSA)}

The PSA, which emerged in the 1960s in Indonesia, is a very popular method for developing state reserves, particularly in Africa. The characteristics of the PSA are that petroleum resources are the host government's properties (often represented by the national utility), while the OCs bear all the risks as well as the cost of exploration. In this model, production is divided into an agreed rate between the concessionaire and the OC (or consortium, made up of domestic and/or foreign companies) (Liu, Zhen, Lin, Yanni \& Fei, 2012).

Through the PSA, the host state contributes to the territorial area to be explored, granting the OC (or consortium) the exclusive right to conduct exploration and production activities; however, without entailing any form of lease or transfer of ownership. The OC then explores the area at its own risk and cost, and receives some of the hydrocarbons produced as a compensation for the borne risk. Thus, if no hydrocarbons are found or the reserves are not tradable, the contract ends without the OC having any right to recover its costs.

If the activity is successful, the consortium will gain the opportunity to recover the costs incurred and make a profit. In addition, the state and national concessionaire receive a share of the production. In this model, two important nomenclatures emerge. The first is Cost Oil, which is the part of the production destined to the consortium, with the purpose of recovering the investments through exploration, development costs, production, administration, and service expenses.

The second is Profit Oil, which is the difference between the total oil produced and the cost recovery oil (Cost Oil). Profit Oil is shared between the concessionaire and the consortium, in accordance with the conditions established in the contract. The tax affects only Profit Oil.

Some characteristics of the production sharing model are described below:

(i) Cost Oil is limited to a maximum percentage of the total amount of oil, generally $50 \%$, and may reach $65 \%$ if development and production costs are not recovered within four to five years after commercial production begins;

(ii) Although Cost Oil is intended for the recovery of investments and total costs incurred, investments in exploration are not taken into account for the eventual increase in the percentage of remuneration;

(iii) Development costs are increased by a factor (uplift) defined in the respective PSA, and amortized at an annual rate of $25 \%$, in the year in which they occur or in the first year of commercial production, whichever is later;

(iv) The only incident tax is the petroleum income tax (IRP). This tax affects the portion of Profit Oil destined to the consortium, a rate that varies between $30 \%$ for domestic companies and $50 \%$ for companies of foreign origin.

\section{Petroleum exploration and production}

The assessment and exploration of oil at sea can be considered part of a multi-stage investment problem. According to Gupta and 
Grossmann (2014), the life cycle of a typical oil field project at sea consists of the following five steps:

(i) Exploration: This activity involves geological and seismic studies, followed by exploratory wells, in order to determine the presence of oil and/or gas;

(ii) Appraisal: This is the drilling of delineation wells to establish the size and quality of the potential field. Preliminary development planning and feasibility studies are also undertaken;

(iii) Development: Following a positive phase of evaluation, this phase aims to select the most appropriate development plan among several alternatives. This stage involves investment and capital intensive investment decisions that include facilities, drilling, and underwater structures, among others;

(iv) Production: After facilities are built and wells drilled, production begins, and gas and/or water can be injected into the field, in order to increase productivity;

(v) Abandonment: This is the last phase of an oil field development project and involves dismantling of the facilities.

In case of positive results in the evaluation phase, development is undertaken; this is a set of activities aimed at enabling the commercial production of oil. According to Fleten, Gunnerud, Hem, and Svendsen (2011), and Dixit and Pindyck (1994), the most important decisions in a petroleum exploration and production project refer to the development phase, in which the bulk of the investment takes place.

\section{I Oil price movement}

According to Fleten, Gunnerud, Hem, and Svendsen (2011), from the year 2000 in, oil prices have been increasingly volatile, thus creating uncertainty as to whether projects can deliver sufficient returns on investment. Thus, the authors state that the price of oil is one of the most important factors in the evaluation of a potential oil field. Similar to the price of other marketable items, the price of oil is governed by supply and demand.

In 2015, the price drop was alarming. According to a report published by the World Bank (2015), the oil price fell approximately 55\% from June 2014 to January 2015, declining from US\$115 per barrel to US\$47 per barrel, ending a period of four years of stability. The average oil price in 2015 was US $\$ 48.67$ per barrel, $48 \%$ lower than the 2014 average of US\$93.17. In January 2016, the price dropped to US\$35.97, reaching US $\$ 45.60$ per barrel in September of the same year.

The changes in oil price are challenging to predict as they fluctuate with new information in the market. Considering this, stochastic processes are useful for forecasting, and consequently to indicate the risk of these forecasts through forecast confidence intervals. Considering such complexity, several researches focused on finding better approximations for the behavior of this variable.

Postali and Picchetti (2006) present a discussion on stochastic processes to evaluate investments in the oil and gas sector. The objective of the authors is to present the advantages and disadvantages of the methods of GBM and moving average reversion in the oil price forecast. According to their results, although the average reversal process may be more accurate to represent the evolution of oil prices over a certain period of time, the GBM approximation does not cause significant valuation errors. Therefore, the results suggest that it is possible to use the GBM as a good method to describe price movement and take advantage of its operational ease.

The stochastic behavior of oil prices, their convenience rate and the risk-free interest rate play decisive roles in the evaluation of oil deposits. In this sense, Kaffel and Abid (2009) present a 
study to assist in the decision-making on the best continuous-time stochastic models for these risk factors. Tests have shown that the GBM with jumps is the best model to forecast the price of oil, when compared to the other commonly used processes.

In addition, many authors use the GBM method and highlight the importance of this method to model the oil price (Al-Harthy, 2007; Aspen, 2011; Brennan \& Schwartz, 1985; Chen Deng, Huang \& Quin, 2015; Liu et al., 2012; Meade, 2010; Mostafaei, Sani \& Askani, 2013; Paddock, Siegel \& Smith 1988). Thus, despite several techniques to model the movement of oil prices, considering the research of the main authors in this subject, it can be concluded that the stochastic model of GBM presents robust approximations, as the standard deviations of the results are within the prediction interval and do not generate significant evaluation errors (Pindyck, 1999).

\section{I.I Geometric Brownian Motion (GBM)}

According to Dixit and Pindyck (1994), the Brownian motion (or Wiener process) is a stochastic process that presents the following three important properties:

(i) This is a Markov process, and therefore the probability distribution for all future values depend only on the present value;

(ii) The process has independent increments. Thus, over a period of time, the probability distribution for the variations in the process is not affected by another time interval; (iii) Changes in the process during any time interval are normally distributed, increasing the variance linearly with time interval.

According to Dixit and Pindyck (1994), a variable $P$ follows a GBM if it follows the stochastic differential equation below, since $\mathrm{P}(0)$ is the known value at $\mathrm{t}=0$ :

$\left(\frac{\mathrm{dP}}{\mathrm{P}}=\alpha \mathrm{dt}+\sigma \mathrm{dz}\right)$

where

$\alpha$ : growth rate (drift);

$\sigma$ : volatility $(\sigma>0)$;

$\mathrm{dz}$ : increment of the Wiener process

$(d z=\varepsilon \sqrt{d t}$, sendo $\varepsilon \sim N(0,1))$

In the GBM, variable $P$ follows a lognormal distribution, since the percentage rate of variation of the stochastic variable $(\mathrm{dP} / \mathrm{P})$ follows a normal distribution with the mean and variance shown below:

$$
(\mathrm{dP} / \mathrm{P}) \sim \mathrm{N}\left(\alpha \mathrm{dt} ; \sigma^{2} \mathrm{dt}\right)
$$

Considering $\mathrm{x}=\mathrm{Ln} \mathrm{P}$ and using Itô's lemma, we obtain:

$$
\left(\mathrm{dx}=\mathrm{d}(\ln \mathrm{P})=\left(\alpha-\sigma^{2} / 2\right) d t+\sigma \mathrm{dz}\right)
$$

Thus, the logarithmic return $\mathrm{d}$ ( Ln P) also has a normal distribution. Therefore, if the logarithm of $\mathrm{P}$ has a normal distribution, $\mathrm{P}$ has a lognormal distribution. Integrating equation (3) results in: 


$$
\begin{aligned}
& \left(\int_{t=0}^{T} d\left(\operatorname{Ln}[P(t)]=\int_{t=0}^{T}\left(\alpha-\sigma^{2} / 2\right) d t+\int_{t=0}^{T} \sigma \mathrm{dz}(\mathrm{t})\right)\right. \\
& \left(\operatorname{Ln}[P(T)]=\operatorname{Ln}[P(0)]+\left(\alpha-\sigma^{2} / 2\right) T+\sigma \mathrm{N}(0,1) \sqrt{T}\right)
\end{aligned}
$$

Assuming risk neutrality, and thus using the risk-free rate (r) instead of the growth rate ( $\alpha)$, we obtain:

$$
\left(\operatorname{Ln}[P(T)]=\operatorname{Ln}[P(0)]+\left(\mathrm{r}-\delta-\sigma^{2} / 2\right) T+\sigma \mathrm{N}(0,1) \sqrt{T}\right)
$$

Through mathematical transformations, equation (6) can be written as follows:

$$
\left(P(T)=P(0) \cdot \exp \left[\left(\mathrm{r}-\delta-\sigma^{2} / 2\right) T+\sigma \mathrm{N}(0,1) \sqrt{T}\right]\right)
$$

In order to determine the variable $\mathrm{P}(\mathrm{T})$ at date $T$, equation (7) indicates that the following four variables need to be defined: initial value $P(0)$, risk free interest rate $(r)$, volatility $(\sigma)$, and the random number $(\mathrm{N}(0,1))$.

According to Dias (2015), if P follows a GBM, considering the initial value of $\mathrm{P}(\mathrm{PO})$, then its future values $\mathrm{P}(\mathrm{t})$ have lognormal distributions with the following mean and variance:

$$
\left(E\left[P(t) \mid P_{o}\right]=P_{o} e^{\alpha t}\right)
$$

$$
\left(\operatorname{Var}\left[\mathrm{P}(\mathrm{t}) \mid \mathrm{P}_{\mathrm{o}}\right]=\mathrm{P}_{\mathrm{o}}{ }^{2} \mathrm{e}^{2 \alpha \mathrm{t}}\left(\mathrm{e}^{\sigma^{2} \mathrm{t}}-1\right)\right)
$$

Assuming risk neutrality, the growth rate $\alpha$ is replaced by the risk premium penalized $(\alpha-\pi)$, where $\pi$ is the risk premium. However, we obtain $(\alpha-\pi)=(r-\delta)$, where $r$ is the risk free rate and $\delta$ is the convenience rate.

The convenience rate is related to the possibility of a product shortage, which could unexpectedly interrupt production and is analogous to the dividend rate of a financial asset; however, in this case, the asset is a commodity (Dias, 2015). The convenience rate can be calculated by the mean of equation (10) (Fleten, Gunnerud, Hem \& Svendsen, 2011).

$\left(\delta(T)=r-\frac{1}{T} \ln \left[\frac{F(P, t, T)}{P(t)}\right]\right)$
Here, $r$ is the risk-free rate, $\mathrm{P}(\mathrm{t})$ the spot price, and $F(P, t, T)$ are the future market prices at a generic instant $t$ for delivery on date $T$.

In the case of risk-neutral GBM, the mean and variance are calculated as follows:

$$
\left(E^{Q}[\mathrm{P}(\mathrm{t})]=P_{o} e^{(\mathrm{r}-\delta) t}\right)
$$

$$
\left(\operatorname{Var}\left[\mathrm{P}(\mathrm{t}) \mid \mathrm{P}_{\mathrm{o}}\right]=\mathrm{P}_{\mathrm{o}}{ }^{2} \mathrm{e}^{2(\mathrm{r}-\delta) \mathrm{t}}\left(\mathrm{e}^{\sigma^{2} \mathrm{t}}-1\right)\right)
$$

\section{Real options}

The decisions referring to oil exploration and production are complex, mainly due to the high number of uncertainties involved (Suslick, Schiozer \& Rodriguez, 2009). According to Schiozer, Ligero and Santos (2004), uncertainties are those that can influence the success of oil exploration and production. Although significantly new methodologies for measuring the uncertainties have been found, they do not accurately define the impact of uncertainties, as this impact varies with time and the amount of information available.

Thus, the ROT emerges as a method of evaluating oil projects, which involve irreversible investment decisions subject to uncertainty (Armstrong, Galli, Bailey \& Couet, 2004). This tool is complementary to the DCF method, in 
order to not disregard its value as a method to evaluate projects.

According to Dias (2004), the real options method can be considered as an optimization problem under uncertainty, where in most practical cases, the net present value (NPV) should be maximized, subject to:

(i) Relevant options (managerial flexibility);

(ii) Market uncertainties (oil price and equipment fees);

(iii) Technical uncertainties (existence of oil, and quality and quantity available).

As highlighted by Helland and Torgersen (2014), the main types of real options in most investment projects are abandonment, timing, expansion, and temporary suspension.

\section{I Binomial method}

Cox, Ross and Rubinstein (1979) propose a simple model of pricing discrete time options, and it is possible to obtain the same results from the Black and Scholes (1973) model using only elementary mathematics. In order to facilitate the development of the model, it is assumed that an asset can take the following two values in the future:

- Su: $S$ multiplied by the upward factor "u" (up);

- $\quad$ Sd: $S$ multiplied by the backward factor "d" (down).

The values of these multiplying factors, represented by "u" and "d", respectively, are based on the volatility $(\sigma)$ of the object asset and the expiration time $(\Delta t)$, as presented in equations (13) and (14), respectively:

$u=e^{(\sigma \sqrt{\Delta t})}$
$d=\frac{1}{u}=e^{(-\sigma \sqrt{\Delta t})}$

The probability of reaching each node is defined by the letter "p," which represents the neutral risk probability or equivalent martingale measure. For Copeland and Antikarov (2001), the risk-neutral probability is only a facilitated method of adjusting the cash flows in order to discount them at a risk-free rate. Thus, the neutral probability to upside risk $\left(\mathrm{p}_{\mathrm{u}}\right)$ and descending risk $\left(p_{d}\right)$ when dividends are obtained, are presented in equations (15) and (16), respectively.

$p_{u}{ }^{\prime}=\frac{e^{\left(r_{c}-\delta_{c}\right) \Delta t}-d}{u-d}$

$p_{d}{ }^{\prime}=1-p_{u}{ }^{\prime}$

where:

$r_{c}:$ risk-free rate in continuous time;

$\delta_{\dot{c}}$ : dividend rate in continuous time.

When the basic asset is the price of a commodity, is the convenience rate in continuous time.

The process is simple. After generating a binomial tree for multiple periods of the basic asset, calculation of the values of the option using this method is similar to the process of resolution of decision trees visually. In addition, it is a process of retroinduction optimization (backwards). The value of the option is calculated as follows:

\section{$F(t)=$ Max. $\lfloor$ to exercise; present value of waiting $\rfloor$}

At the expiration date $(t=T)$, the value of the option is:

$F(T)=\operatorname{Max} .[$ to exercise $; 0]$

\section{Research method}

The methods used were modeling and simulation. The proposed problem is based on the economic analysis of a real oil exploration and production project, more specifically, on the feasibility analysis of the development of an oil field. Considering this, real data obtained from one of the companies participating in the contract was used. 
In order to develop systematization for solving the problem of modeling and simulation, a structure was elaborated to support the analysis of the project, under the perspective of the traditional method of analysis of investments, risk, and real options. This structure is outlined in Figure 1.

First of all, geological data, such as fluid and rock properties, field characteristics, and field seismic data were selected, in order to calculate the field production profile. The following project data were then collected: planned schedule for CAPEX, schedule of expected values for OPEX, government participations, contract properties, and discount rate. In order to analyze the feasibility of the development of the field, the cash flows of the production period were obtained. Through the traditional method of investment analysis, such as NPV and IRR indicators, the feasibility of the field was analyzed.

The second phase (phase II) started with the forecast of oil prices, using the GBM. Uncertainties referring to the variables CAPEX, OPEX, and production profile were inserted into the model, in order to investigate their impact on the result obtained in the first phase. The variables that impact the most were selected, and finally, the risk analysis was performed. At this stage, decisions can be made within a probabilistic scenario.

The first stage of the last phase (phase III) refers to the choice of a real options model that can translate the effect of the variables that impact the most, selected in the previous phase. Next, the parameters required to create the event tree are calculated. The next step is to incorporate flexibility into the project and calculate the value of the option. The flexibility considered in the present study is postponing the necessary investments in the development of the oil field under evaluation.

Finally, in order to provide a more intuitive tool to decision-makers, a binomial tree is developed. According to Brandão, Dyer and Hahn (2005), this tool presents a tree with nodes that represent the decision that borrowers must adopt to maximize project value, as uncertainties are resolved during their economic life. 


\section{Phase I}

\section{Data:}

- CAPEX e OPEX

- Discount rate

- Fiscal regime

- Contractual arrangements

- Average price

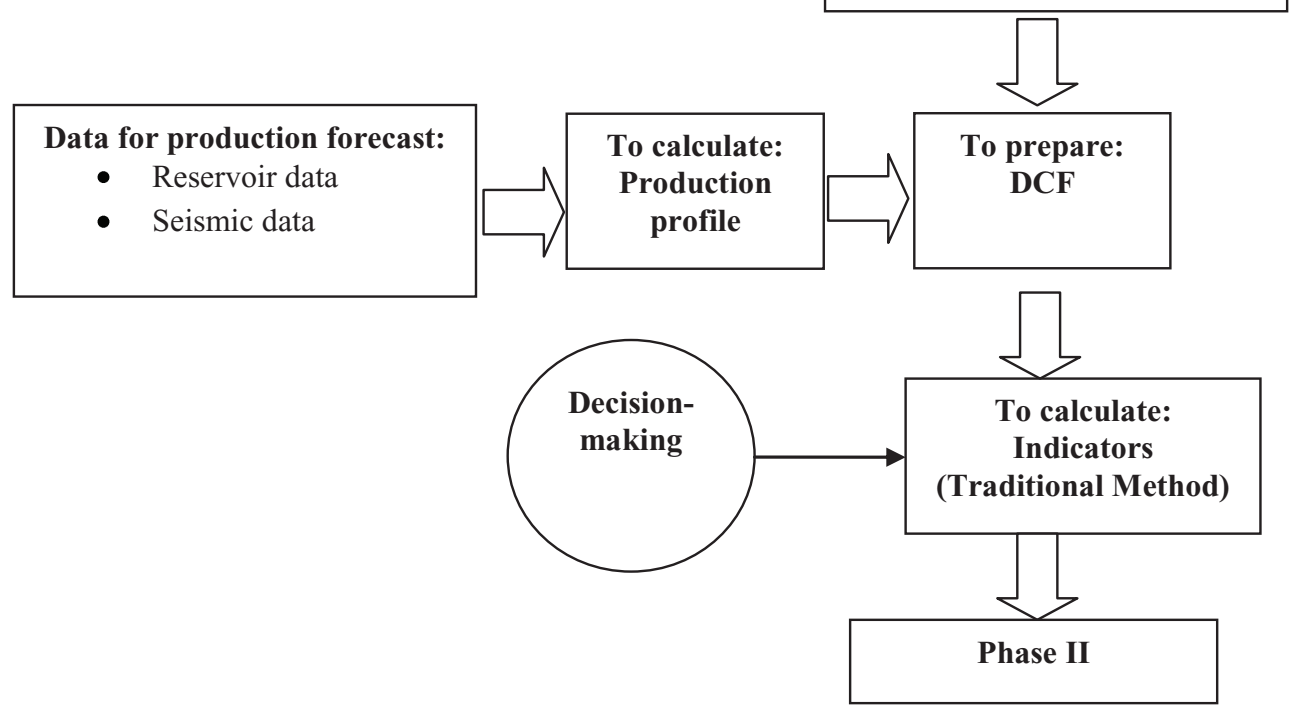

Phase II

- $\quad$ Oil Price Forecast (MGB)

- Define distributions (uncertain variables)
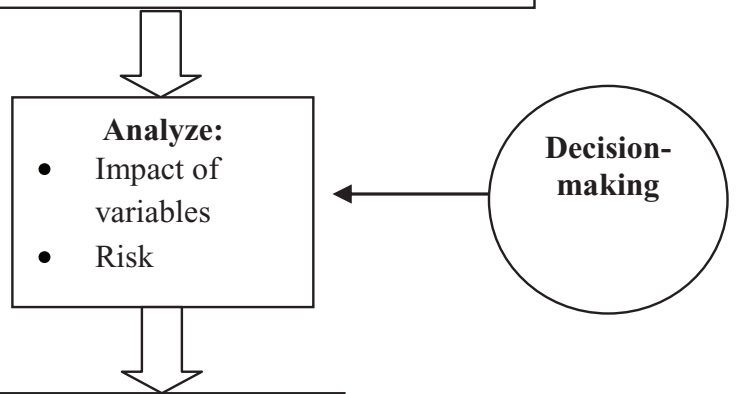

\section{Phase III}

Phase III
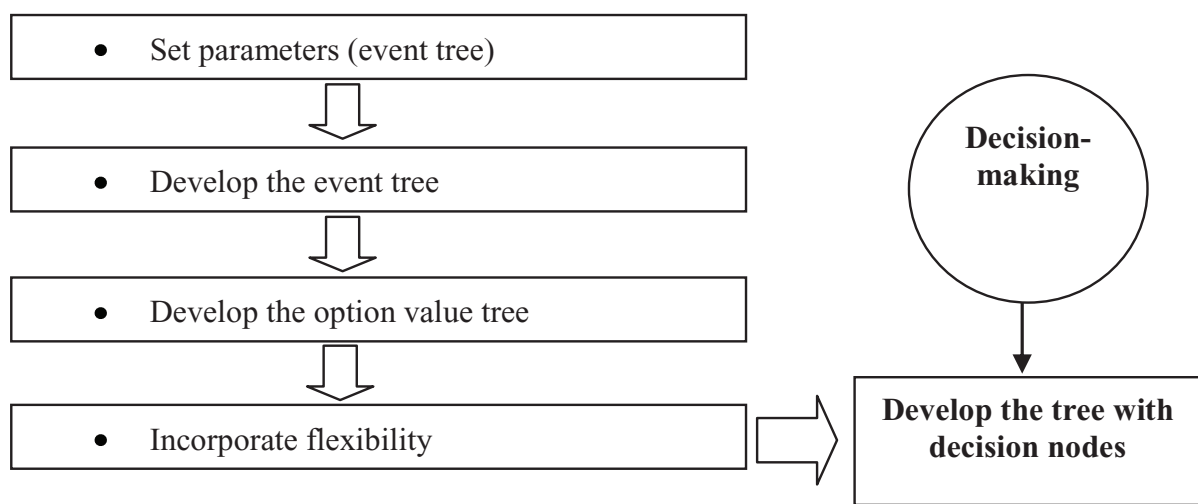

Figure 1. Structure for the evaluation of the oil field 


\section{Discussion of results}

\section{I Phase I - Traditional project analysis}

As mentioned earlier, the national concessionaire holds the rights to hydrocarbons and its form of association with the consortium is governed by the PSA. The consortium is made up of two companies, one foreign and one national, in which the rightful percentage is $40 \%$ and $60 \%$, respectively.

At the first moment, in which the objective is to analyze the feasibility of the project through a deterministic model, it is assumed that the average price of a barrel of oil during the production period is equal to the initial price, being $\mathrm{P}(0)=$ US\$59.80, which is the value referring to the price of a barrel of oil in June 2015 .

The total expenses of the studied field are shown in Table 1.
Table 1

\section{E\&P Expenses}

\begin{tabular}{ll}
\hline Variables & Expenses \\
\hline Investments in exploration & $\$ 963,200,000.00$ \\
CAPEX & $\$ 5,817,020,000.00$ \\
OPEX & $\$ 6,907,950,000.00$ \\
\hline
\end{tabular}

Petrel $^{\circ}$ and Eclipse ${ }^{\circ}$ software were used to forecast oil production. These forecasts represent three possibilities for field recoveries. The "base case" forecast recovers 280 million barrels from ten production wells, three gas injectors, and three water injectors. The "optimistic case" recovers 460 million barrels from 14 production wells, four gas injectors, and three water injectors. The "pessimistic case" recovers 150 million barrels through six production wells, three gas injectors, and two water injectors. Daily production forecast in thousands of barrels per day (kBOPD) is presented in Figure 2.

\section{Oil Production kBOPD}

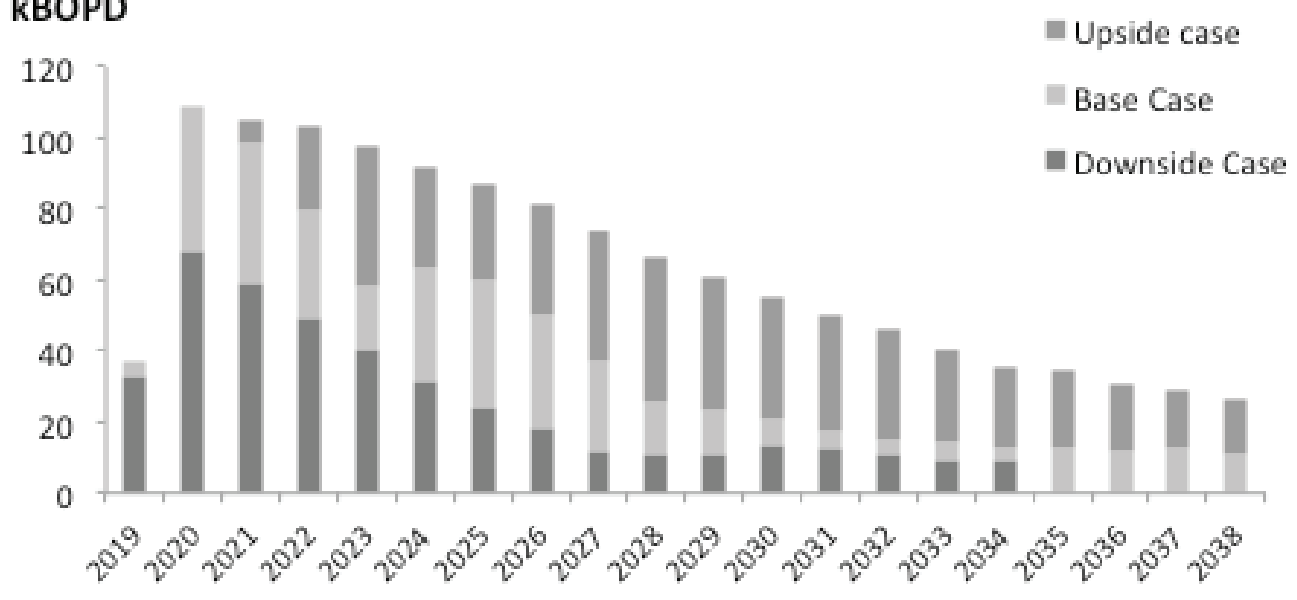

Figure 2. Field production profile

Considering the deterministic model, the "base case" will be used. In the PSA, cash flows of the consortium (in dollars) are calculated as shown in Table 2. 
Table 2

\section{Consortium cash flow model (PSA)}

\begin{tabular}{l}
\hline Total revenue \\
\hline (-) OPEX \\
(-) CAPEX \\
(-) Oil income tax (IRP) \\
(=) Consortium cash flow \\
\hline
\end{tabular}

Since the scope of this study focuses on the feasibility analysis, values referring to each item of the cash flow are not specified.

\section{I.I Traditional method}

Through traditional indicators (NPV and IRR) it is possible to analyze the feasibility of the project. The weighted average cost of capital (WACC) used is $10 \%$, which is the value used by the consortium in the evaluation of development of oil fields in the country which is under analysis.

Table 3 shows NPV and IRR values, from the perspective of the consortium for the PSA.

Table 3

Indexes (traditional evaluation method)

\begin{tabular}{ll}
\hline Indexes & Value \\
\hline NPV & $\$-800,570,000.00$ \\
IRR & $2.03 \%$ \\
\hline
\end{tabular}

Therefore, based on the traditional method of investment analysis, the consortium is advised to not declare the commerciality of the analyzed field, as the negative NPV indicates infeasibility of the field development. As mentioned previously, in this manner, the consortium will lose all the investments made in exploration activities, with no possibility of recovery of these values.

\subsection{Phase II - Risk analysis}

Considering the objective of analyzing whether price is actually an impacting variable in the final result, as well as evaluating the importance of the other input variables of the project (CAPEX, OPEX, and production forecast), a sensitivity analysis was undertaken considering these variables. The project was then evaluated from a risk perspective.

\subsection{Sources of uncertainty}

Based on the knowledge of company managers, the main sources of uncertainty considered in the project were the following variables:

- Market uncertainty: price of a barrel of oil, CAPEX, and OPEX; and

- Technical uncertainty: production forecast.

Dias (2005), and Pindyck and Rubinfeld (1991) performed the Dickey-Fuller unit root test in respect to the oil price series and did not find evidence that the GBM hypothesis can be rejected. Taking this into consideration, the same test was conducted on the price data set of this study, and according to the aforementioned authors, the p-value were found to be: (a) 0,1810 for a random walk; (B) 0,2772 for a random walk with a displacement e; (C) 0,2377 for a random walk with a deterministic trend shift (GBM).

Therefore, the GBM is selected as the technique to be used to predict the price of oil during the production period of the field. Thus, if $P$ follows a GBM considering the initial value of $\mathrm{P}$, then its future values $\mathrm{P}(\mathrm{t})$ have lognormal distributions with the mean and variance calculated using equations (8) and (9).

In order to define the risk-free rate, the yield on the United States of America (the US) Treasury Bond with a 10 -year maturity was determined for the period January 2000 to August 2015. The average real annual rate of interest was found to be $2.65 \%$.

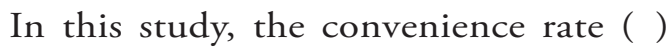
was calculated using equation (10), considering $r$ as the risk free rate, $P(t)$ as the spot prices, and $\mathrm{F}(\mathrm{P}, \mathrm{t}, \mathrm{T})$ as the future market prices at a generic time $t$ for a delivery date T. Monthly data of the WTI oil (NYMEX, traded in New York) from September 1989 to April 2015 were used. Dias (2005) highlights that an alternative to the calculation of $\mathrm{P}(\mathrm{t})$ is to use the future market as a 
proxy for the current value. Therefore, the future price for delivery in one month was used as an approximation of the spot price. Considering the future market price, the WTI oil price data were used for delivery in month 18 . Thus, the annual convenience rate was $2.92 \%$. This value is consistent with Pickles and Smith (1993), who recommend using $\delta=r$ (risk free rate).

According to Dias (2015), if prices follow a GBM, the parameters of volatility $(\sigma)$ and growth $(\alpha)$ can be estimated with a trivial linear regression. Thus, these parameters can be calculated using equations (19) and (20):

$\alpha=N\left\{E[\operatorname{Ln}[P(t)\rfloor-\operatorname{Ln}[P(t-1)]]+\sigma^{2} / 2 N\right\}$

$\left.\sigma^{2}=N \operatorname{Var}[\operatorname{Ln}[P(T)]-\operatorname{Ln}[P(t-1)]] 20\right)$

These parameters are usually reported in annual units (\% per year), but data is often daily, weekly, or monthly, where $\mathrm{N}$ is the number of periods per year of data observation. In the present case, $\mathrm{N}$ will be equal to 12 , as monthly data will be analyzed on the price of a barrel of oil.

In order to determine the growth rate (annual) $\alpha$ and the volatility (annual) $\sigma$, we used WTI oil (IMF, 2015) in real values (US\$ June 2015) deflated using the Consumer Price Index as a deflator of the US dollar with monthly data from July 2000 to June 2015 . The annual growth rate was $7.84 \%$ and the volatility was $34.12 \%$ per year.

The volatility found in this study was higher than the volatility found by Lund (1999) and Fleten, Gunnerud, Hem, and Svendsen (2011), which can be explained by the high volatility of the oil price in recent years, though it is in close proximity to the volatility $(33.07 \%)$ found by Dias (2015). The initial price considered is for June 2015, quoted at US\$59.80.

Finally, parameters are replaced in equations (8) and (9), and the expected values for the price and diversion of oil during the production period are calculated.

The distributions and parameters that were used are shown in Table 4.

Table 4

\section{Distributions}

\begin{tabular}{lcc}
\hline Variables & Distribution & Parameters \\
\hline Price & Lognormal & L (mean GBM, deviation GBM) \\
Production forecast & Triangular & $\mathrm{T}$ (pessimistic case, base case, optimistic case) \\
CAPEX & Triangular & $\mathrm{T}(-10 \%$, base case, $+20 \%)$ \\
OPEX & Triangular & $\mathrm{T}(-10 \%$, base case, $+30 \%)$ \\
\hline
\end{tabular}

\subsubsection{Sensitivity analysis}

The stochastic variables were inserted into the model and using the CrystalBall ${ }^{\circ}$ software, 10.000 iterations were simulated.

The sensitivity analysis of the chosen variables shows that price is the variable that has the most impact in the final result. The other variables were not significant in the final result. Analyzing the effect of price fluctuation (in dollars) on NPV (in millions of dollars) shown in figure 3 , it is assumed that decision-making (when one does not have the option to delay) can be based on two bands, as shown in Table 5 . 


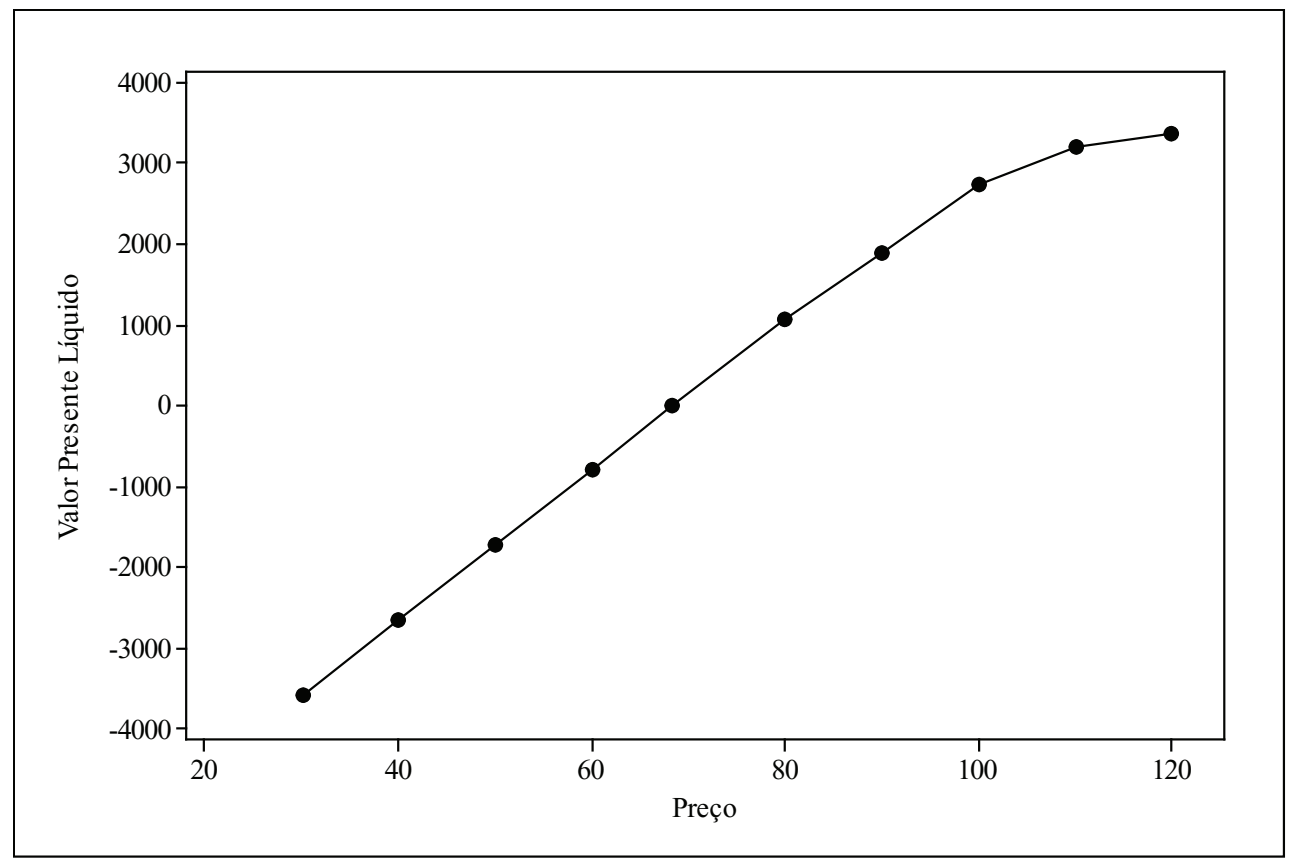

Figure 3. NPV x Price

Table 5

\section{Decision rule}

\begin{tabular}{ll}
\hline Price & Decision \\
\hline $\mathrm{P}<$ US\$68.30 & Do not invest \\
$\mathrm{P} \geq$ US\$68.30 & Invest \\
\hline
\end{tabular}

Therefore, from the perspective of the consortium, if managers choose to base their decisions on a deterministic analysis, disregarding the risks and flexibilities of the project, and in a scenario of oil prices above US\$68.30, the area under evaluation may be declared commercial.

\subsubsection{Project risk}

After entering the distribution of the most sensitive variable of the project (price of oil barrel) through Monte Carlo simulation, CrystalBall ${ }^{\circ}$ software provides the distribution of the possible NPV results.

Figure 4 shows that the probability of feasibility, that is, of obtaining an NPV above zero, is equal to $13.21 \%$. However, considering decision making using the NPV metric, managers would probably not choose to invest in the development of the field.

Thus, we can observe that the negative results presented in both contracts are mainly reflected in the price of oil, which has been showing a steep decline in recent years. Thus, Helland and Torgersen (2014), Gupta and Grossman (2014), and Fleten, Gunnerud, Hem, and Svendsen (2011) highlight that the fluctuation of oil prices are one of the most important variables in the analysis of investments in oil projects. Also confirming the justifications for the unfavorable scenario of investments in oil in the country where the field is located, is published by the Energy Information Administration (2015).

Considering the importance of the valuation price of a real asset, only this variable will be considered in the calculation of project volatility, similar to Paddock, Siegel, and Smith (1988), and Dixit and Pindyck (1994). 


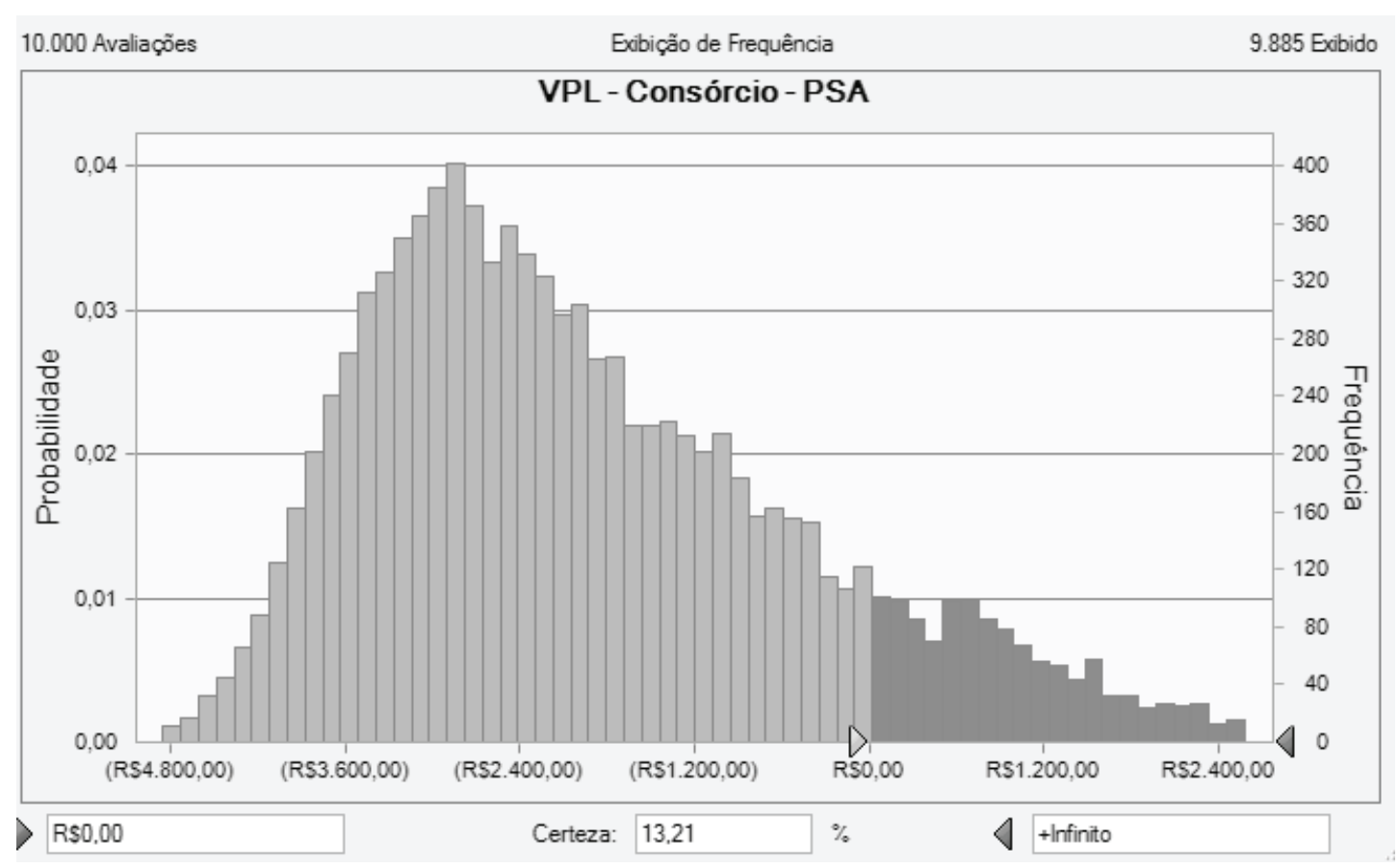

Figure 4. Project risk

\subsection{Phase III - The value of flexibility}

At this stage, an application of the multiperiod binomial method will be undertaken as the object of this study, in order to capture the value of the flexibility of this project. However, the binomial model will be used to represent the process of price diffusion of the barrel of oil, which is the basic asset. Considering the present project, it is assumed that, from 2015 on, the consortium will have five years to begin the development of the field. Thus, calculating the value of the option to postpone investments (waiting option) for the development of the oil field under the perspective of the PSA is preferred.

The parameters for calculating the value of flexibility are presented in Table 6.

Table 6

\section{Parameters of RSC}

\begin{tabular}{lc}
\hline Parameters & Values \\
\hline Initial price $(\mathrm{P} 0)$ & $\$ 59.80$ \\
Volatility & $34.12 \%$ \\
Convenience fee (per year) & $2.92 \%$ \\
Risk free rate (per year) & $2.65 \%$ \\
Field life & 20 \\
Time interval in the tree $(\Delta t)$ & 1 \\
Tree stages & 5 \\
Expiration time $(\mathrm{T})$ & 5 \\
Upward factor (u) & 1.4066345 \\
Downward factor $(\mathrm{d})$ & 0.7109167 \\
Neutral probability to risk $(\mathrm{p})$ & $41.11 \%$ \\
$(1-\mathrm{p})$ & $58.89 \%$ \\
\hline
\end{tabular}




\subsection{Real Options}

Having calculated the parameter values, the binomial method for option pricing was developed according to the four phases outlined below, based on the equations described in section 4.1:

(i) Generate the binomial tree of the basic asset V;

(ii) Generate the event tree for the value of the developed field: the value of the developed asset is a function of the price of the barrel of oil; (iii) Calculate the value of the asset using the option at the terminal nodes $(\mathrm{t}=\mathrm{T})$;

(iv) Calculate backwards, the values of the asset using the option of waiting in the predecessor nodes $(\mathrm{t}<\mathrm{T})$ until the initial date $(\mathrm{t}=0)$.

Based on the values of the asset with the hold option, the binomial tree was developed, including lines in which the optimal decision is highlighted (see Table 7), considering that this is a more intuitive tool for the decision maker.

Table 7

\section{Binomial tree (standby option)}

\begin{tabular}{|c|c|c|c|c|c|c|}
\hline & 2015 & 2016 & 2017 & 2018 & 2019 & 2020 \\
\hline Oil barrel prices & $\$ 59.80$ & $\$ 84.12$ & $\$ 118.32$ & $\$ 166.44$ & $\$ 234.11$ & $\$ 329.31$ \\
\hline Decision & Standby & Standby & Standby & Invest & Invest & Invest \\
\hline Oil barrel prices & & $\$ 42.51$ & $\$ 59.80$ & $\$ 84.12$ & $\$ 118.32$ & $\$ 166.44$ \\
\hline Decision & & Standby & Standby & Standby & Invest & Invest \\
\hline Oil barrel prices & & & $\$ 30.22$ & $\$ 42.51$ & $\$ 59.80$ & $\$ 84.12$ \\
\hline Decision & & & Standby & Standby & Standby & Invest \\
\hline Oil barrel prices & & & & $\$ 21.49$ & $\$ 30.22$ & $\$ 42.51$ \\
\hline Decision & & & & Standby & Standby & Quit \\
\hline Oil barrel prices & & & & & $\$ 15.27$ & $\$ 21.49$ \\
\hline Decision & & & & & Standby & Quit \\
\hline Oil barrel prices & & & & & & $\$ 10.86$ \\
\hline Decision & & & & & & Quit \\
\hline
\end{tabular}

The binomial tree shows the possible scenarios of the future price of oil barrel and the indication to the decision maker. For example, if in 2016 the oil price reached US\$84.12, in order to maximize the results, the indicated decision is to expect a better time, although the scenario shows that investing in this would provide positive results. It should be noted that the method used considers that the other variables did not change with the passage of time.

It can be observed that the period with the highest number of favorable investment scenarios is in the year 2020, which is the year of expiration of the option. This occurs due to the high uncertainty captured in the binomial diffusion, as the price variance increases with the time horizon such that more extreme price scenarios are present in 2020.

The trigger price also reached US\$92.40 in 2015. In other words, for oil price levels above this value, immediate investment in the development of the oil field is recommended. The graph of the trigger curve for the period 2015-2020, the expiration date of the option, is shown in Figure 5. 


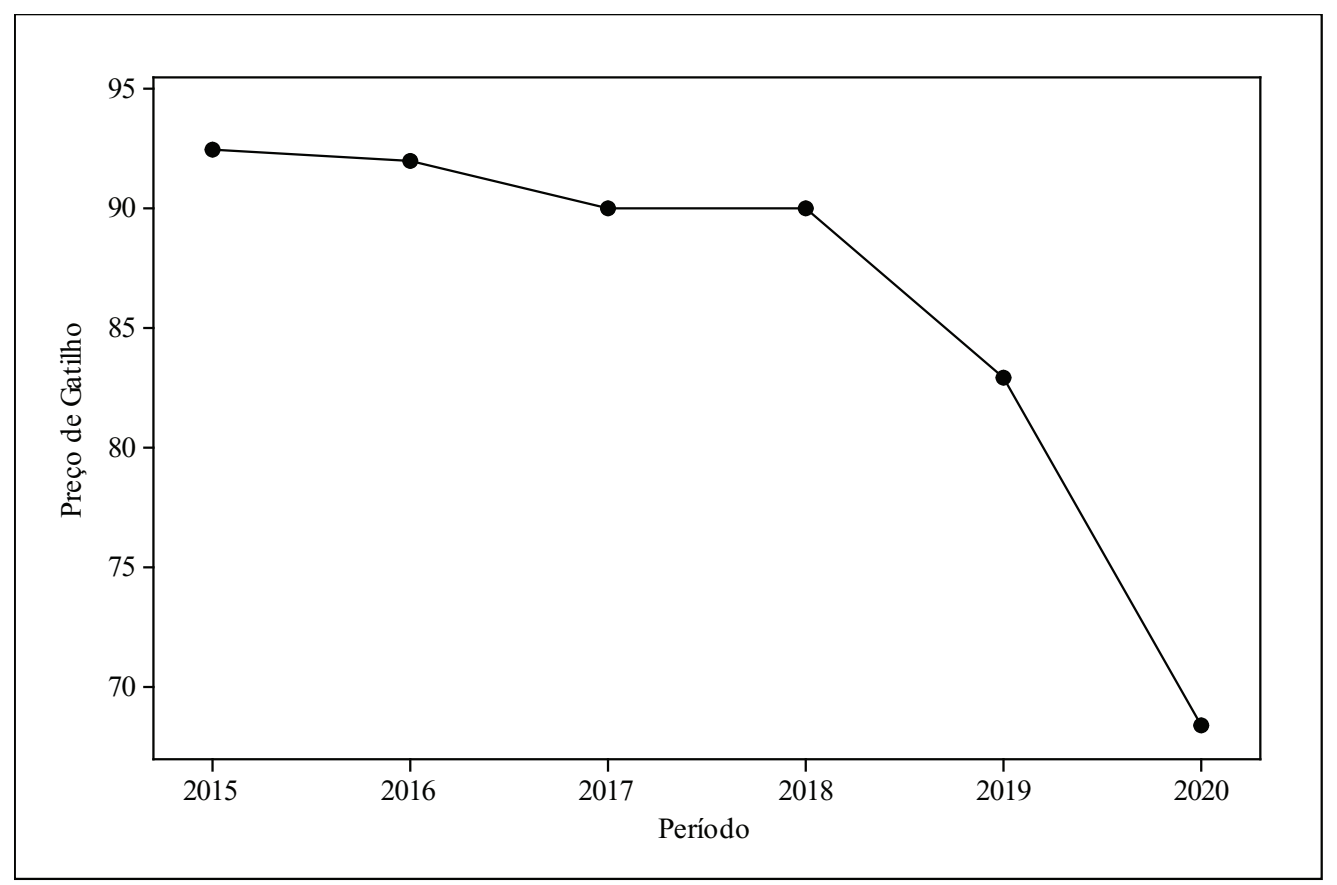

Figure 5. Trigger curve

It can be observed from Figure 5 that, at the expiration date of the option (2020), the trigger price is equal to US\$68.30, the value from which the project becomes viable.
The value of the field was calculated at $\$ 924,230,000.00$, using the option. Figure 6 shows the value of the field calculated using the option (in millions of dollars) versus the price of a barrel of oil.

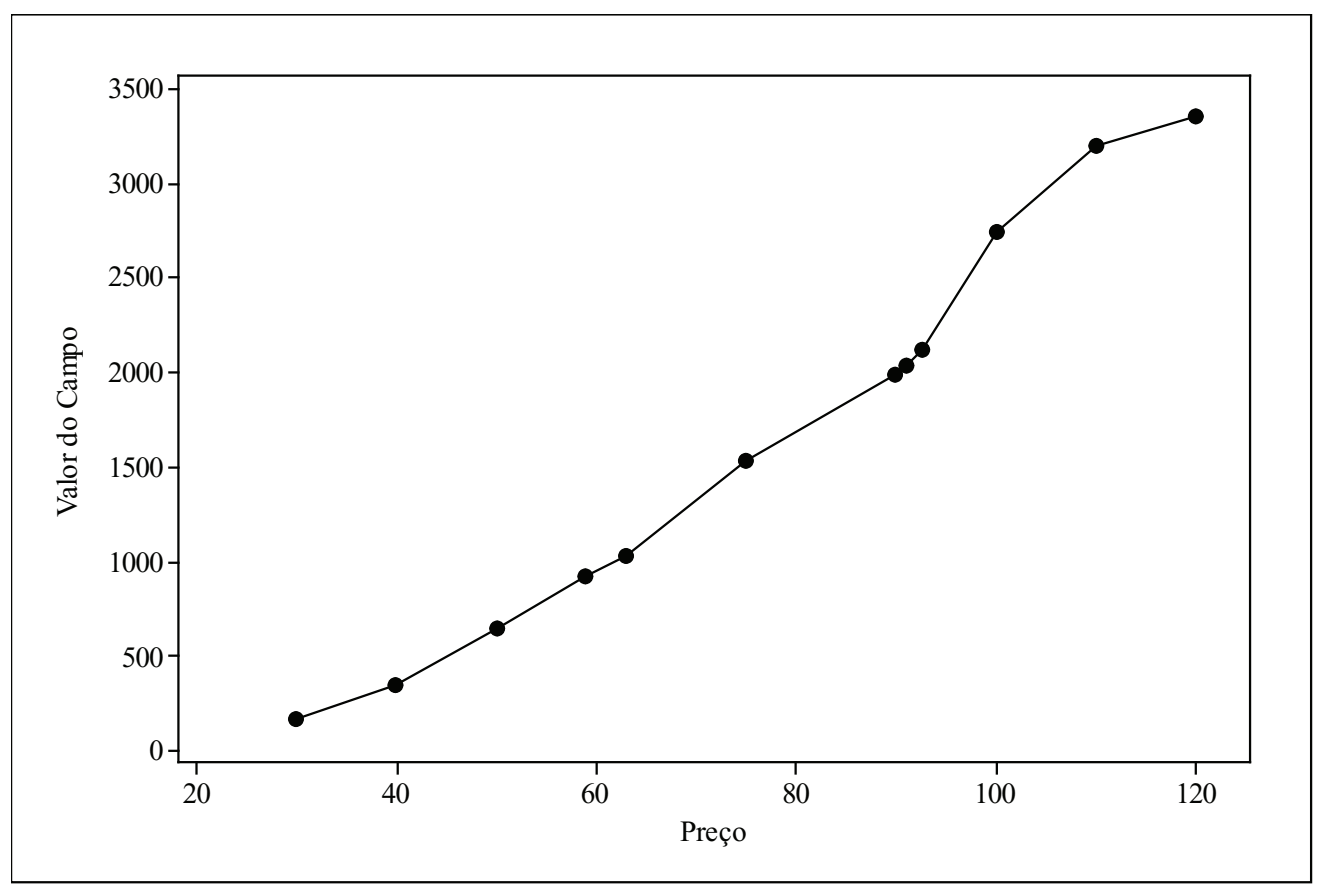

Figure 6. Value of field with option $\mathrm{x}$ price 
Therefore, it is possible to verify the importance of the manager, in order to obtain the option to postpone the development of the field, as the results obtained show that the asset substantially appreciated in this case, when compared to the result obtained through the traditional method.

Finally, Figure 7 shows the influence of volatility on the value of the asset. The value of the oil field are in millions of dollars.

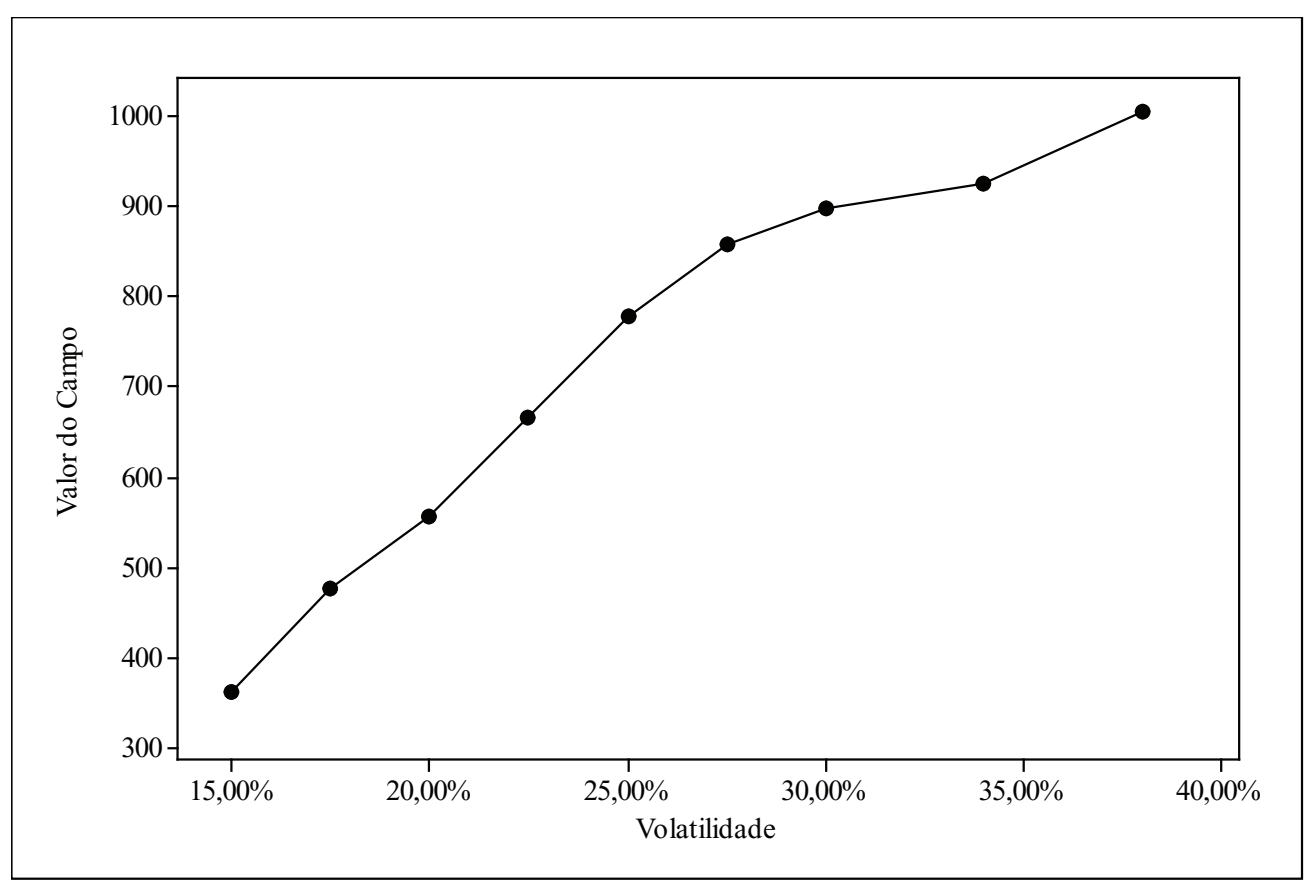

Figure 7. Value of the field with the option x volatility

As shown in Figure 7, the value of the field is positively influenced by the volatility. This result corroborates the analysis that uncertainty of the project has the potential to add value to it, if the manager has the flexibility to delay the development of the field.

\section{Conclusions}

This study was based on a real case of economic analysis of investments, with the objective to analyze the feasibility of the development of an oil field located in Africa, where the PSA was adopted.

The production profile of the oil field under analysis was created from a 3D model, developed through Petrel ${ }^{\circ}$ and Eclipse software. The use of this technique provided more precision in the economic feasibility analysis of the project, as this method is better represented for the field production potential. In addition, this procedure contributed to literature, as several analyses of oil investments are based on less robust techniques, such as zero-scale models.

However, in order to approximate the investment analysis to the real behavior of the project, the GBM technique was applied to forecast oil prices. Using this approach, a low oil price scenario was found during the production period, and the intensity of this movement significantly influenced the project's infeasibility when managerial flexibility was disregarded.

Based on the traditional method, the project's NPV was equal to -US\$800,570,000, which suggests that the field should not be developed. Next, we found that price is the most influential variable in the feasibility analysis. Thus, through the GBM, the price of a barrel of oil 
was entered for risk analysis, which resulted in a low likelihood of feasibility of field development (13.21\%), also indicating the decision to not commerciality declare the field.

Finally, the ROT was used to investigate the value of managerial flexibility in the field feasibility analysis. From the point of view of real options, it was found that volatility creates value for the project, as the value of the asset increased from US $\$ 800,570,000$ to US\$924,230,000, when managerial flexibility was considered. Thus, the indication to maximize the value of the asset is expected by a favorable scenario of oil prices.

The analyses are similar to the reality of low investments in the pre-salt areas of the country in question. This can be explained by comparing the average oil prices for 2015 and 2016, with the trigger prices for the periods, where the option can be exercised, which suggests the manager to wait for better conditions of the price of the barrel, and therefore, to postpone the investments.

However, it should be noted that the project's volatility was considered to have originated in the price volatility of the oil barrel. This is a contour condition of the present study. Thus, as a future research, it is suggested that other variables could be included to obtain less imprecise estimates of the volatility of each project. In addition, another possibility of research is based on the development of the same analysis, but for service contract with risk, and then comparing the results with the present study.

\section{References}

Al-Harthy, M. H. (2007). Stochastic oil price models: Comparison and impact. The Engineering Economist, 52(3), 269-284.

Aspen, L. (2011). Oil price models and their impact in project economics (Master Thesis). University of Stavanger, Stavanger, Norway.

Armstrong, M., Galli, A., Bailey, W., \& Couet, B. (2004). Incorporating technical uncertainty in real option valuation of oil projects. Journal of Petroleum Science and Engineering, 44 (1-2), 67-82.

Brennan, M. J., \& Schwartz, E. S. (1985). Evaluating natural resource investments. Journal of Business, 58(2), 135-157.

Black, F., \& Scholes, M. (1973). The pricing of options and corporate liabilities. Journal of Political Economy, 81, 637-659.

Brandão, L., Dyer, J., \& Hahn, W. (2005). Using binomial decision trees to solve real-option valuation problems. Decision Analysis, 2(2), p. 69-88.

Chen, R., Deng, T., Huang, S., \& Qin, R. (2015). Optimal crude oil procurement under fluctuating price in an oil refinery. European Journal of Operational Research, 245(2), 438-445.

Cox, J., Ross, S., \& Rubinstein, M. (1979). Option price: A simplified approach. Journal of Financial Economics, 7(3), 229-264.

Copeland, T. E., \& Antikarov, V. (2001). Opçôes reais: Um novo paradigma para reinventar a avaliação de investimentos. Rio de Janeiro: Campus.

Costa Lima, G. A., \& Suslick, S. B. (2006). Estimation of volatility of selected oil production projects. Journal of Petroleum Science and Engineering, 54(3-4), 129-139.

Dias, M. A. G. (2004). Valuation of exploration and production assets: An overview of real options models. Journal of Petroleum Science and Engineering, 44(1-2), 93-114.

Dias, M. A. G. (2005). Opçóes reais híbridas com aplicaçóes em petróleo (Tese Doutorado). Departamento de Engenharia Industrial, Pontifícia Universidade Católica do Rio de Janeiro, Rio de Janeiro, Brazil.

Dias, M. A. G. (2015). Análise de investimentos com opçôes reais: Teoria e prática com aplicaçôes 
em petróleo e em outros setores (Vol. 2: Processos estocásticos e opçôes reais em tempo contínuo). Rio de Janeiro: Interciência.

Dixit, A. K., \& Pindyck, R. S. (1994). Investment under Uncertainty. New Jersey, Princeton: University Press.

Energy Information Administration - EIA. (2015). Independent Statistics and Analysis. Retrieved from www.eia.gov.

Fleten, S., Gunnerud, V., Hem, O. D., \& Svendsen, A. (2011). Real option valuation of offshore petroleum field. Journal of Real Options, $1,1-17$.

Gupta, V., \& Grossmann, I. E. (2014). Multistage stochastic programming approach for offshore oilfield infrastructure planning under production sharing agreements and endogenous uncertainties. Journal of Petroleum Science and Engineering, 124, 180-197.

Gupta, V., \& Grossmann, I. E. (2011). Offshore oilfield development planning under uncertainty and fiscal considerations. [Working paper, p. 1-43]. Carnegie Mellon University, Pittsburg, EUA. Retrieved from https://pdfs.semanticscholar. org/ceb9/1220e69c2f48184e901136646932a8 $2 \mathrm{f} 5 \mathrm{dc} 3 . \mathrm{pdf}$

Helland, J., \& Torgersen, M. (2014). The Value of Petroleum Exploration under Uncertainty: $A$ Real Option Approach (Master Tesis). Norwegian School of Economics, Norway.

Kaffel, B., \& Abid, F. (2009). A methodology for the choice of the best fitting continuoustime stochastic models of crude oil price. The Quarterly Review of Economics and Finance, 49(3), 971-1000.

IMF- International Monetary Fund. (2015). IMF Primary Commodity Prices. Retrieved from www. $\mathrm{imf.org/external/np/res/commod/index.aspx}$
Liu, M., Zhen, W., Lin, Z., Yanni, P., \& Fei, X. (2012). Production Sharing Contract: An analysis based on an oil price stochastic process. Petroleum Science, 9(3), p.408-415.

Lund, M. W. (1999). Real Options in Offshore Oil Field Development Projects. [Working Paper N-4035, p. 1-27]. Natural Gas Marketing \& Supply, Statoil, Stavanger, Norway. Retrieved from http://www.realoptions.org/papers 1999/ LUND.PDF

Meade, N. (2010). Oil prices - Brownian motion or mean reversion? A study using a one year ahead density forecast criterion. Energy Economics, 32(6), 1485-1498.

Mostafaei, H., Sani, A. A. R., \& Askari, S. (2013). A methodology for the choice of the best fitting continuous-time stochastic models of crude oil price: The case of Russia. International Journal of Energy Economics and Policy, 3(2), 137-142.

Paddock, J. L., Siegel, D. R., \& Smith, J. L. (1988). Option valuation of claims on real assets: The case of offshore petroleum leases. Quarterly Journal of Economics, 103, p. 479- 508.

Postali, F. A. S., \& Picchetti, P. (2006). Geometric brownian motion and structural breaks in oil prices: A quantitative analysis. Energy Economics, 28(4), 506-522.

Pickles, E., \& Smith, J. L. (1993). Petroleum Property Evaluation: A binomial lattice implementation of option pricing theory. Energy Journal, 14(2), 1-26.

Pindyck, R. S., \& Rubinfeld, D. L. (1991). Econometric Models and Economic Forecasts (3rd ed.). New York: McGraw-Hill, Inc.

Pindyck, R. S. (1999). The Long-Run Evolution of Energy Prices. Energy Journal, 20(2), p. 1-27.

Salomão, M. C., \& Grell, A. P. (2001). Uncertainty in production profiles on the basis of geostatistic 
characterization and flow simulation. SPE Latin American and Caribbean Petroleum Engineering Conference. Buenos Aires, Argentina, SPE 69477.

Schiozer, D. J., Ligero, E. L, \& Santos, J. A. M. (2004). Risk assessment for reservoir development under uncertainty. The Journal of the Brazilian Society of Mechanical Sciences and Engineering, 26(2), 213-217.

\section{Supporting agencies:}

Fapemig - Fundação de Amparo à Pesquisa de Minas Gerais

CNPq - Conselho Nacional de Desenvolvimento Científico e Tecnológico

CAPES - Coordenação de Aperfeiçoamento de Pessoal de Nível Superior

\section{About the authors:}

1. Marcelo Nunes Fonseca, Master's Degree in Production Engineering, Universidade Federal de Itajubá.

Brazil. E-mail: marcelonunes21@yahoo.com.br

ORCIID

(iD) 0000-0002-3651-8747

2. Edson de Oliveira Pamplona, Doctorate Degree in Management, Fundação Getúlio Vargas. Brazil.

E-mail: pamplona@unifei.edu.br

ORCID

(iD) 0000-0001-6085-0240

3. Paulo Rotela Junior, Doctorate Degree in Production Engineering, Universidade Federal de Itajubá.

Brazil. E-mail: paulo.rotela@gmail.com

\section{ORCIID}

(D) 0000-0002-4692-7800

4. Victor Eduardo de Mello Valério, Master's Degree in Production Engineering, Universidade Federal de Itajubá. Brazil. E-mail: victor.dmv@gmail.com

ORCIID

(iD) 0000-0003-4127-5951

\section{Contribution of each author:}

\begin{tabular}{|c|c|c|c|c|}
\hline Contribution & $\begin{array}{c}\text { Marcelo Nunes } \\
\text { Fonseca }\end{array}$ & $\begin{array}{c}\text { Edson de } \\
\text { Oliveira } \\
\text { Pamplona } \\
\end{array}$ & $\begin{array}{l}\text { Paulo Rotela } \\
\text { Junior }\end{array}$ & $\begin{array}{c}\text { Victor Eduardo } \\
\text { de Mello } \\
\text { Valério } \\
\end{array}$ \\
\hline 1. Definition of research problem & $\sqrt{ }$ & $\sqrt{ }$ & & \\
\hline $\begin{array}{l}\text { 2. Development of hypotheses or research questions } \\
\text { (empirical studies) }\end{array}$ & $\sqrt{ }$ & $\sqrt{ }$ & $\sqrt{ }$ & \\
\hline \multicolumn{5}{|c|}{ 3. Development of theoretical propositions (theoretical Work) } \\
\hline 4. Theoretical foundation/ Literature review & $\sqrt{ }$ & & & $\sqrt{ }$ \\
\hline 5. Definition of methodological procedures & $\sqrt{ }$ & $\sqrt{ }$ & $\sqrt{ }$ & $\sqrt{ }$ \\
\hline 6. Data collection & $\sqrt{ }$ & & & \\
\hline 7. Statistical analysis & $\sqrt{ }$ & & & $\sqrt{ }$ \\
\hline 8. Analysis and interpretation of data & $\sqrt{ }$ & & $\sqrt{ }$ & $\sqrt{ }$ \\
\hline 9. Critical revision of the manuscript & & $\sqrt{ }$ & $\sqrt{ }$ & \\
\hline 10. Manuscript Writing & $\sqrt{ }$ & $\sqrt{ }$ & $\sqrt{ }$ & $\sqrt{ }$ \\
\hline
\end{tabular}

Suslick, S. B.,Schiozer, D., \& Rodriguez, M. R. (2009). Uncertainty and risk analysis in petroleum exploration and production. Terrae, 6(1), 30-41.

World Bank (2015). Commodity Markets Outlook. Retrieved from documents.worldbank.org/ curated/pt/380281468125701579/pdf/938350 WP0Box3805a0commodity0Jan2015.pdf 